\title{
Patrimonio alimentario y turismo cultural en el cantón Guamote provincia de Chimborazo
}

DOI: https://doi.org/10.33262/ap.v3i3.1.82

\begin{abstract}
(c) (1) (8)(2)
Food heritage and cultural tourism in the Guamote canton, Chimborazo province
\end{abstract}

Jhon Dennys Guaraca Quishpe. ${ }^{1}$, Rafael Santiago Ortega Quijosaca. ${ }^{2}$, Daniel Marcelo Guerrero Vaca. ${ }^{3}$ \& Jessica Alexandra Marcatoma Tixi. ${ }^{4}$

\begin{abstract}
.
Introduction: Cultural tourism currently represents an opportunity for the development of localities that today do not have a consolidated tourist offer but that, nevertheless, have all the potential to offer their visitors quality tourist and cultural experiences. Objective: Contribute to territorial tourism planning based on the potential of food heritage through the generation of a tourism perspective in community leaders who have not yet made use of their cultural assets, as well as key guidelines to begin a process that involves the municipality, the private sector and the community in general. Methodology: The research had a cross-sectional quantitative exploratory character whose main actors were the inhabitants of the rural area and representatives of the municipality. Results: The multiple correspondence analysis with a reliability of $93.1 \%$ in its first profile showed that the indigenous dishes of the inhabitants are beans, corn, cheese, mellocos and potatoes with guinea pig and corn chicha, however these They have not been promoted as dishes offered to tourists and as one of the constant alternatives in the food places, on the other hand it was known that the municipality does not generate an integral marketing

\footnotetext{
${ }^{1}$ Universidad Nacional de Chimborazo, Facultad de Ciencias Políticas y Administrativas, Riobamba, Ecuador, jguaraca@unach.edu.ec, https://orcid.org/0000-0001-6791-7735

2 Escuela Superior Politécnica de Chimborazo, Facultad de Salud Pública, Riobamba, Ecuador, rortega @ espoch.edu.ec, https://orcid.org/0000-0001-9479-3459

3 Universidad Nacional de Chimborazo, Facultad de Ciencias Políticas y Administrativas, Riobamba, Ecuador, daniel.guerrero@unach.edu.ec, https://orcid.org/0000-0002-4889-4985

${ }^{4}$ Universidad Nacional de Chimborazo, Facultad de Ingeniería, Riobamba, Ecuador, jessica.marcatoma @ espoch.edu.ec, https://orcid.org/0000-0001-9531-3234
} 
that allows the inhabitants to possess their businesses as a primary economic line, either due to lack of support for the gastronomic area or the lack of leaders who only focus on tourism progress. Conclusions: The food heritage and cultural tourism serve as strategic axes to boost the tourist offer of the Guamote canton, on the one hand, created a workspace and on the other, offering visitors not only enjoy its natural landscapes and cultural activities but also delicious food. that is prepared in the town.

Keywords: Food tourism, gastronomy, cultural heritage.

\section{Resumen.}

Introducción: El turismo cultural en los últimos años representa una oportunidad para el desarrollo de localidades que hoy no cuentan con una oferta turística consolidada pero que, sin embargo, cuentan con todo el potencial para ofrecer a sus visitantes experiencias turístico-culturales significativas y de calidad. Objetivo: Contribuir a la planificación turística territorial con base al potencial del patrimonio alimentario a través de la generación de una perspectiva turística en los líderes comunitarios que aún no han hecho uso de sus activos culturales, así como orientaciones claves para comenzar un proceso que involucre al municipio, al sector privado y a la comunidad en general. Metodología: El estudio fue de tipo exploratorio cuantitativo de corte transversal cuyos actores principales fueron los habitantes de la zona rural y representantes de la municipalidad. Resultados: El análisis de correspondencias múltiples con una confiabilidad del 93,1\% en su primer perfil evidenció que los platos autóctonos de los habitantes son las habas, choclo, queso, mellocos y las papas con cuy y la chicha de maíz, sin embargo estos no han sido potenciados como platillos ofertados a turistas y como una de las alternativas constantes en los sitios de comida, por otra parte se conoció que la municipalidad no genera un marketing integral que permita a los habitantes posesionar sus negocios como una línea económica primaria bien sea por falta de apoyo al área gastronómica o por la falta de dirigentes que solo se enfoquen en el progreso turístico. Conclusiones: El patrimonio alimentario y turismo cultural fungen como ejes estratégicos para dinamizar la oferta turística del cantón Guamote por un lado crenado espacion de trabajo y por otro ofertando a los visitantes no solo disfrutar de sus paisajes naturales y actividades culturales sino también de la deliciosa comida que se prepara en el cantón.

Palabras claves: Turismo alimentario, gastronomía, patrimonio cultural.

\section{Introducción.}

El turismo cultural en los últimos años representa una oportunidad para el desarrollo de comunas y localidades que hoy no cuentan con una oferta turística consolidada pero que, sin embargo, cuentan con todo el potencial para ofrecer a sus visitantes experiencias turístico-culturales significativas y de calidad. Según la Organización Mundial del Turismo los principales beneficios de su práctica derivan nuevas oportunidades de empleo, atenúa la pobreza, frena el éxodo rural entre los jóvenes y los subempleados así 
como cultiva un sentimiento de orgullo entre los miembros de las comunidades, ofreciendo también un poderoso incentivo para conservar y potenciar el patrimonio cultural inmaterial, ya que los ingresos que genera pueden reconducirse hacia iniciativas que ayuden a su vez a una supervivencia de largo plazo. (Respaldiza, 2014).

El lazo entre el patrimonio alimentario y el turismo cultural ha sido denotado de gran jerarquía debido a su valor turístico y gastronómico, puede entenderse el mismo como un puente entre el pasado y el presente de una sociedad, dejando herencias llenas de costumbres y tradiciones que materializan su historia y al mismo tiempo es símbolo de su transición. A menudo se relaciona el turismo cultural con las identidades autóctonas de un pueblo, a medida que supone el reconocimiento intergeneracional por parte de los miembros de una sociedad. Se ha señalado también que el patrimonio alimentario es cambiante y que se va construyendo a través de la selección de elementos y componentes seleccionados, de modo que el patrimonio cultural puede entenderse como una construcción de saberes. (Inga, 2020).

Según Villalva (2020)." A nivel internacional tanto el turismo cultural como su patrimonio alimentario permiten identificar una serie de características únicas de cada región, denotando una serie de tradiciones y costumbres propias que caracterizan a cada país o región a nivel mundial, mostrándose ante los ojos del mundo como una oportunidad económica que invita a los habitantes y turistas al crecimiento de los pueblos y nacionalidades".

La dinámica turística y gastronómica a nivel nacional constituye un cúmulo de conocimientos, técnicas y saberes ancestrales impulsados por la variedad de platillos autóctonos, los mismos que con el pasar de los años han venido mejorando con nuevas técnicas vanguardistas, no obstante, la verdadera esencia culinaria se hereda de generación en generación, la misma se encuentra ligada al turismo cultural debido a la migración de personas que gustan recorrer el mundo probando y viviendo nuevas experiencias siendo los pueblos rurales el lugar de encuentro entre la historia, turismo y gastronomía.

Las estimaciones de crecimiento del turismo en los años iniciales del siglo XXI siguen siendo impresionantes, tanto sobre el fenómeno como sobre la propia industria. El análisis de la literatura existente arroja mucha luz sobre el crecimiento y la popularidad del turismo. El Ecuador y sus pueblos mágicos han palpado un crecimiento muy importante gracias a su belleza natural y cultural incomparable a nivel mundial pues constantemente recibe turistas nacionales e internacionales en todas las temporadas, por lo que los ingresos derivados de la actividad representan uno de los principales rubros dentro de los ingresos no petroleros. (Turistica, 2015).

Una de las maravillas culturales, naturales, gastronómicas y sociales se consolidan en la provincia de Chimborazo, este colectivo posee una gran diversidad de especies de flora, fauna y paisajes andinos, no dejando de lado su patrimonio alimentario, el componente cultural que existe en esta localidad representa la manifestación de hábitos y creencias 
culturales y varias comunidades rurales han convertido al turismo en una alternativa sustentable de ingresos, tan solo inspirados por los halagos que reciben de turistas internacionales y nacionales y por las experiencias personales de cuando han visitado otros tesoros del país. (Mosquera, 2015).

Según Vimos (2012). "El turismo cultural del cantón encabezado por el carnaval de Guamote compone la lectura de expresiones y cosmovisiones populares a través de los distintos actos enmarcados en la celebración, que al igual que muchas celebraciones de la zona Andina se convierten en un espacio de igualdad y choque pluricultural, donde el patrimonio alimentario y el turismo cultural son los principales actores".

En la provincia de Chimborazo existen diferentes atractivos turísticos y gastronómicos que forman parte indiscutibles los pueblos y nacionalidades indígenas. Guamote cuenta con una inmensa variedad de productos y atractivos culturales que sin duda dinamizan la economía de la zona, no obstante, el desconocimiento de su gastronomía tradicional y explotación de sus recursos naturales han hecho de esta una problemática que a lo largo de los años se ha venido tratando con la parte técnica turística del cantón.

Bajo esta dinámica, la afluencia de turistas ha incrementado la demanda culinaria autóctona de la localidad siendo los principales platillos las sopas de granos (haba, maíz, arveja); locros de papas, ocas, mellocos y cebada, en especial las habas tiernas, papas con achiote, machica con manteca de chancho, acompañado de horchata elaborada de arroz de cebada, dulce de guayaba o chicha de avena. (Guamote, 2019).

Por estas razones, la presente investigación pretende apoyar a la planificación turística territorial con base al potencial del patrimonio alimentario a través de la generación de una perspectiva turística en los líderes comunitarios que aún no han hecho uso de sus activos culturales así como orientaciones claves para comenzar un proceso que involucre al municipio, al sector privado y a la comunidad en general.

\section{Metodología.}

La investigación fue de tipo exploratorio debido al análisis preliminar que mantiene la gastronomía guamoteña, si bien es cierto Guamote es un cantón que goza de atractivos ancestrales y culturales únicos que aún no han sido potenciados en el sector turístico y gastronómico, Según el método de investigación se consideró la misma de tipo cuantitativo pues las informaciones recolectadas de los habitantes de las zonas rurales del cantón permitieron caracterizar las costumbres, materias primas, formas de obtención de materias primas, tecnología culinaria y conservación de alimentos, en cuanto a la línea de tiempo, el estudio fue de corte transversal ya que se desarrolló durante el según trimestre del año.

\section{Población y Muestra}

Se trabajó con un colectivo de 42505 habitantes en la zona rural del cantón Guamote según la información del Instituto Nacional de Estadísticas y Censos INEC, para delimitar 
la muestra se trabajó con la técnica de muestreo aleatorio simple del campo probabilístico al $90 \%$ de confianza obteniendo como resultado a 96 habitantes rurales.

Por otro lado, se trabajó con un colectivo secundario de 5 representantes del área de turismo del GAD Municipal del cantón Guamote para medir la percepción de apoyo al turismo cultural.

\section{Técnicas e Instrumentos de recolección de datos}

La encuesta fue la técnica de recolección de datos apoyada en un cuestionario cerrado de 25 preguntas que abarcan dimensiones como costumbres, materias primas, formas de obtención de materias primas, tecnología culinaria y conservación de alimentos, de forma adicional se utilizó una entrevista estructurada a representantes del municipio mediante un cuestionario abierto donde los funcionarios indicaron su percepción de apoyo al turismo cultural del cantón.

\section{Técnicas estadísticas}

El estudio exploratorio de la información caracterizó las dimensiones como costumbres, materias primas, formas de obtención de materias primas, tecnología culinaria y conservación de alimentos, de forma adicional permitió describir la percepción de apoyo al turismo cultural por parte de las autoridades del cantón.

\section{Resultados.}

Tras el análisis de las encuestas aplicadas a los habitantes de la zona rural del cantón se evidenció en el bloque de datos generales que el $55 \%$ de las personas cuentan con edades entre 40 y 65 años, apenas el $21 \%$ indicaron encontrarse en el intervalo de 18 a 25 años, el $52 \%$ se identificaron con género femenino y el $62,5 \%$ son de estado civil casado.

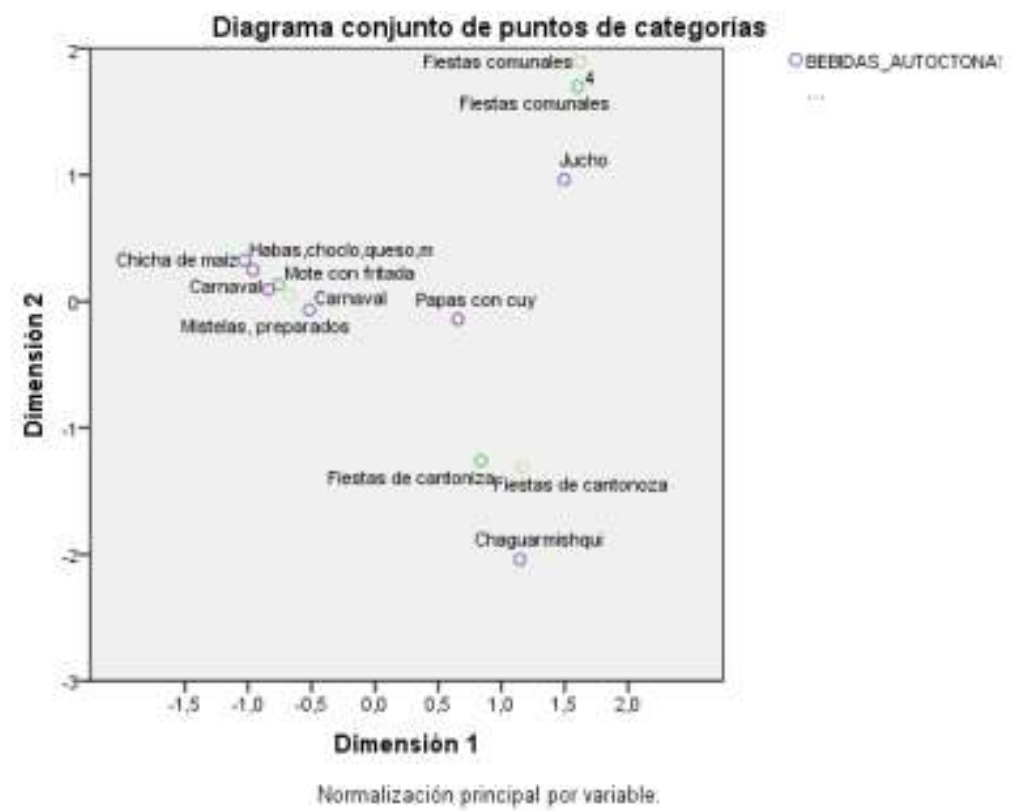

Gráfico 1: Diagrama conjunto de puntos de categorías del modelo de correspondencias múltiples Fuente: Autores 
Con relación a la dimensión costumbres, el perfil construido con una confiabilidad del 93,1\% indicó que los platos autóctonos de los habitantes son las habas, choclo, queso, mellocos y las papas con cuy, como bebida preparan tradicionalmente la chicha de maíz, además indicaron que el carnaval es una de las fechas más importantes para su colectivo y es cuando preparan comida típica.

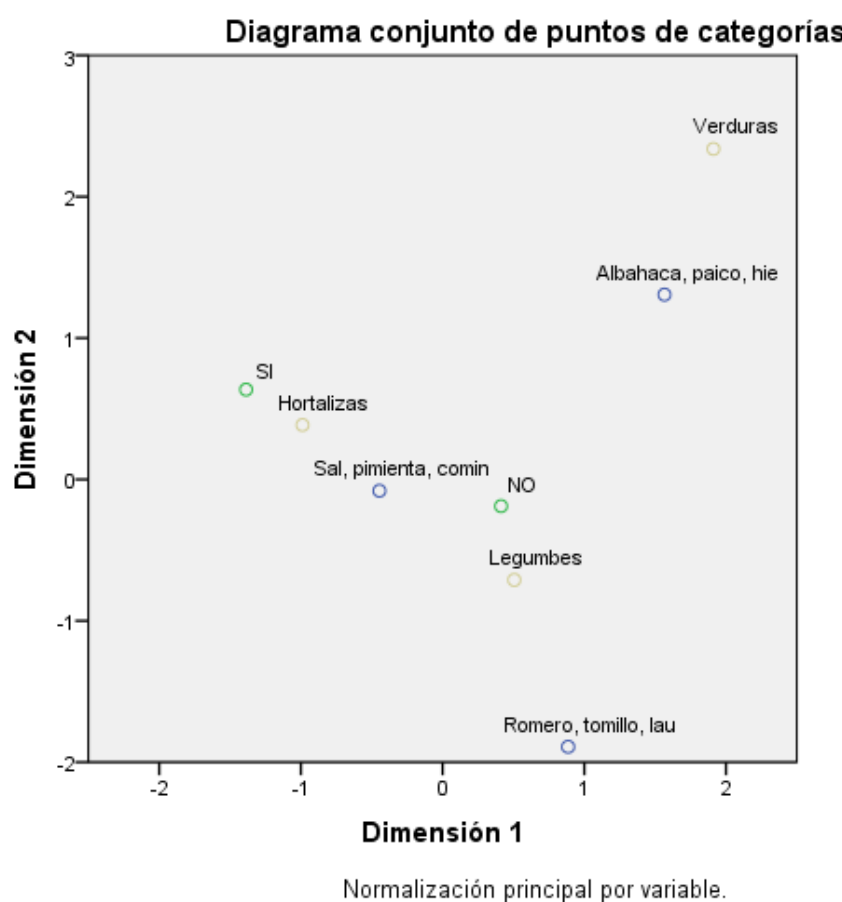

Gráfico 2: Diagrama conjunto de puntos de categorías del modelo de correspondencias múltiples Fuente: Autores

La dimensión materias primas con una fiabilidad del 76,3\% evidenció que los habitantes utilizan como materia prima principal para la elaboración de sus platos típicos a las hortalizas (papas, remolacha, camote y cebolla) y legumbres (arveja, vainita, fréjol, lenteja, garbanzo) en condimentos prima la sal, pimienta y comino.

La tecnología culinaria destacó que el $60,4 \%$ de los habitantes preparan sus alimentos típicos al menos una vez por semana en cocina de leña frente a un 52,1\% que realizan el mismo proceso, pero en cocinas de gas. En líneas de conservación de las carnes el $67 \%$ de los habitantes mencionaron que utilizan la técnica del ahumado.

En relación con las actividades que ejecuta la municipalidad del cantón en líneas de turismo y sostenibilidad de la gastronomía se evidenció la falta de marketing para integrar los múltiples agentes individuales para que cooperen en lugar de competir y llevar a cabo una planificación turística integral. El análisis de competitividad; aprovecha las ventajas de las nuevas tecnologías e internet teniendo como premisa que el sector turístico nacional se convertirá en un mercado cada vez más competitivo donde únicamente los destinos bien dirigidos liderarán el mercado.

Otro desencadenante de la carencia de una planificación turística integral por parte de la municipalidad es la ausencia de un registro de afluencia de turistas y del castro turístico generado por la visita de migrantes, sin embargo tras la entrevista realizada a la técnica 
del departamento turístico justifica estos problemas al indicar que en años anteriores la municipalidad no contaba con un grupo de funcionarios dedicados a esta línea y no es hasta inicios del año 2021 que constituyen como una necesidad la creación del departamento de turismo, a la par mencionaron que no conocían la diferencia entre gastronomía típica y tradicional y que no tenían ejecutado ningún proyecto de sostenibilidad del patrimonio alimentario, en relación al impulso de actividades por promocionar la gastronomía local indicaron haber socializado los platillos tradicionales a través de canales de televisión sobre todo cuando el alcalde y el equipo de festividades promocionan el carnaval de Guamote que fue reconocido como patrimonio cultural inmaterial desde el año 2015, en líneas de conocer los factores que impiden difundir el turismo gastronómico mencionaron que en años pasados la municipalidad no contaba con personal encargado para turismo y las actividades ligadas a promocionar al cantón solo se ejecutaban en fiestas de cantonización y de carnaval, reconocieron la necesidad de ligarse con especialistas gastronómicos para potenciar los sabores ancestrales y ubicarlo como uno de los destinos turísticos de quienes gustan conocer lugares únicos en su cultura.

\section{Discusión}

Según, México(2015),"Los viajes turísticos de nacionales y extranjeros motivados por conocer, comprender y disfrutar el conjunto de rasgos, elementos distintivos, espirituales, materiales, intelectuales y afectivos que caracterizan a una sociedad junto con la gastronomía propia de la zona se constituyen como la combinación perfecta para posesionar el turismo cultural de un colectivo específico".

Como resultado de una sociedad que avanza la gastronomía de los pueblos y comunidades rurales de un colectivo ha ido modernizándose con el paso de los años, la tecnificación de platillos ha posesionado a muchos de los lugares como sitios de concurrencia masiva acarreando turistas y dinamizando la economía local, sin embargo a pesar de que el turismo es un aliado para el crecimiento de las sociedades, no en todos los lugares se dispone de una visión por posicionar a gastronomía tradicional y esta falencia puede derivarse de la falta de planificación de los gobiernos autónomos que los lideran, a ello sumado las intenciones de emprendimiento individual de sus comunidades y la falta de comunicación con técnicos en el área turística evidencian pocos resultados de crecimiento turístico.

El cantón Guamote es un claro ejemplo de los pueblos que cuentan con un sin número de atractivos culturales y naturales que no demandan de una fecha específica para que exista una masiva afluencia turística pues los recursos naturales como la Cueva de luterano, Rio Guamote, Mirador de Ushubug, Piedras blancas, Complejo lacustre Atillo, Paramo Pull Quishuar, Dunas de arena, Fuente de agua señor de la misericordia, festividades del Pauca Raymi, Inti Raymi y Carnaval de Guamote en Febrero, Fiestas en honor al patrono religioso San Juan en junio, fiestas de cantonización en agosto, fiestas de fin de año y año nuevo, y las ferias indígenas de los días jueves reciben turistas de forma constante, y en 
la zona no existe una oferta formal de servicios de alimentos y bebidas como restaurantes o cafeterías que permitan degustar la comida típica y tradicional que permita un intercambio cultural y gastronómico entre los habitantes de la región y de la localidad,

A pesar de la negativa de los habitantes por difundir su cultura, Guamote recibe anualmente turistas internacionales de Holanda, Argentina, España y EEUU en su mayoría de género masculino con edades entre 36 a 45 años, quienes en el estudio "Diseño de un corredor turístico patrimonial para difundir la oferta turística del cantón Guamote" mencionaron que les gustaría realizar actividades como campamento y agroturismo sin embargo, indicaron que entre las desventajas del sitio se encuentra la falta de restaurantes que expendan platos típicos de la zona que les permita degustar las especialidades culinarias que son exclusivas del sector y la reducida gama de alojamientos, por lo que son evidentes las oportunidades de negocio para los habitantes principalmente en las áreas de hotelería y gastronomía. (Quinchi, 2015),

Ante la necesidad identificada se espera que los lideres municipales, encargados de turismo local y provincial generen convenios de trabajo que les permita capacitar en temas gastronómicos a los habitantes rurales que gustan de preparar estas delicias y que serían una de las principales atracciones de propios y extraños. A la par invitar al personal administrativo de hoteles y posadas a presentar en los menús de sus locales la variedad de comida del sector.

Por otra parte, hay que destacar que los medios digitales fomentan un crecimiento significativo que conseguirá maximizar beneficios económicos con el incremento de turistas quienes eligen sus destinos de viaje a través de plataformas virtuales que se han convertido en una herramienta muy utilizada al momento de escoger un destino a visitar, por otra parte, los medios digitales facilitan la difusión de información turística y gastronómica haciendo que el turista viva una mejor experiencia.

\section{Conclusiones}

- El patrimonio alimentario funge como eje estratégico para dinamizar la oferta turística del cantón Guamote permitiendo a los visitantes no solo disfrutar de sus paisajes naturales y actividades culturales sino también de la deliciosa comida que se prepara en el cantón, socializando lo cotidiano de la localidad como agregado de valor a la oferta, de tal manera que el patrimonio alimentario es un complemento para la interrelación del turismo cultural y el comportamiento del consumidor, pues el mismo interrelaciona la satisfacción de necesidades y deseos del turista con interés cultural, a través de un crecimiento humanista y de conocimiento de otras culturas.

- El turismo cultural por su parte puede generar nuevas oportunidades de empleo en la localidad, atenuar la pobreza, así como cultivar un sentimiento de orgullo entre los miembros de las comunidades. El turismo, además, ofrece también un poderoso incentivo para conservar y potenciar el patrimonio cultural inmaterial, ya que los ingresos que genera pueden reconducirse hacia iniciativas que ayuden 
a su vez a la supervivencia de las tradiciones a largo plazo y como fundamento para promover inversiones públicas, privadas y comunitarias en favor el flujo de demanda actual.

\section{Referencias bibliográficas.}

Baray, H. Á. (2006). Introdución a la metodología de la investigación (Edición electrónica ed.).

GAD’S. (2019). GAD’S.

INEN. (s.f.).

INEN. (2006). NTE INEN 0616: Harina de trigo. Requisitos. Obtenido de NORMATÉCNICAECUATORIANANTE

INEN616:200: https://studylib.es/doc/5531663/nte-inen-0616--harina-de-trigo.-requisitos

Inga, C. F. (2020). Patrimnonio cultural inmaterial como fastor de desarrollo turistico del cantón Colta. Kairos, 37-38.

México, S. d. (2015). Turismo cultural. Escuela Superior Politecnica de Chimborazo, 112 $-120$.

Mosquera, D. R. (Mayo de 2015). UNIVERSIDAD POLITÉCNICA SALESIANA SEDE QUITO. Obtenido de https://dspace.ups.edu.ec/bitstream/123456789/9602/1/UPS-QT07869.pdf

Paredes, D. (2010). El tarwi ( Lupinus mutabilis) aspetos socioeconòmicos nutricionales y culturales. Scielo.

Quinchi, M. R. (2015). DISEÑO DEL CORREDOR TURÍSTICO PATRIMONIAL PARA DIFUNDIR LA OFERTA TURÍSTICA DEL CANTÓN GUAMOTE, PROVINCIA DE CHIMBORAZO. Universidad Nacional de Chimborazo, 120 130.

Turistica, T. P. (2015). Ecuador Potencia Turistica.

Villalva, M. (2020). Saberes ansestrales gastronómicos y turismo cultural. Cumbres, 6769.

VIMOS, E. (2012). Universidad Politécnica Salesiana.

World Health Organization;United Nations University. (2007). Protein and amino acid requirements in human nutrition.

Zamora Mora, V., Soares, P., Echeverria, C., Hernández , R., \& Mijangos, C. (2015). Composite chitosan/Agarose ferrogels for potential applications in magnetic hyperethermia. Gels., 1, 69-80. 
Rodríguez, A. (2015). Turismo urbano como motor en las ciudades. Recuperado el 16 de marzo de 2018. Disponible en URL: http://www.trcimplan.gob.mx/blog/turismourbano-como-motor-en-las-ciudades.html

Blanco, R. (2018). Turismo urbano. Recuperado el 16 de marzo de 2018. Disponible en URL: http://www.inforural.com/turismo/cultural/urbano/

Gutiérrez \& Pérez. (2014). Métodos para el análisis del potencial turístico del territorio rural. Recuperado el 17 de marzo de 2018. Disponible en URL: http://www.redalyc.org/html/2631/263137781016/

Organización Mundial del Turismo. (2007). Entender el turismo. Recuperado el 13 de marzo de 2018 de glosario básico. Disponible en URL: http://media.unwto.org/es/content/entender-el-turismo-glosario-basico

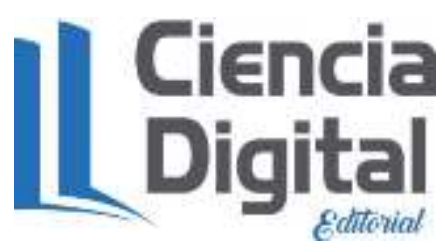




\section{PARA CITAR EL ARTÍCULO INDEXADO.}

Guaraca Quishpe, J. D., Ortega Quijosaca, R. S., Guerrero Vaca, D. M., \& Marcatoma Tixi, J. A. (2021). Patrimonio alimentario y turismo cultural en el cantón Guamote provincia de Chimborazo. AlfaPublicaciones, 3(3.1), 129-139. https://doi.org/10.33262/ap.v3i3.1.82

\section{Ligital}

El artículo que se publica es de exclusiva responsabilidad de los autores y no necesariamente reflejan el pensamiento de la Revista Alfa Publicaciones.

El artículo queda en propiedad de la revista y, por tanto, su publicación parcial y/o total en otro medio tiene que ser autorizado por el director de la Revista Alfa Publicaciones.
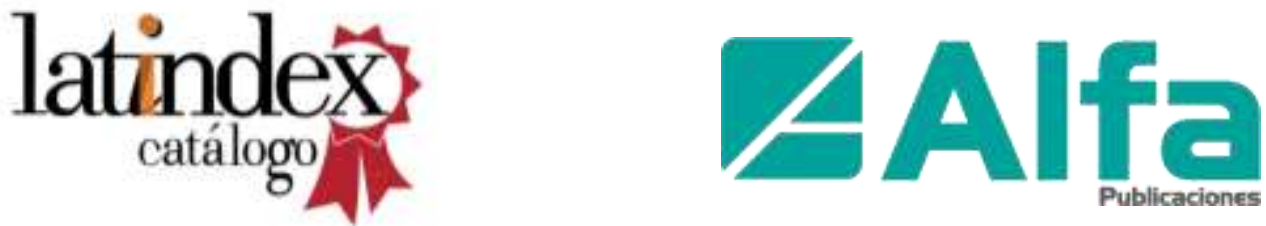